\title{
Prevalence of Solid Neoplasms Diagnosed Between the Years of 2011 to 2016 and Oncologically Treated at the University Hospital of Santa Maria
}

\author{
Fernando Borges da Silva ${ }^{\mathrm{a}, \mathrm{b}}$, Marcelo Binato ${ }^{\mathrm{b}, \mathrm{c}}$, Juliano Tonezer da Silva ${ }^{\mathrm{d}, \mathrm{e}}$, \\ Clandio Timm Marques ${ }^{\mathrm{f}, \mathrm{g}, \mathrm{h}}$, Tiango Aguiar Ribeiro ${ }^{\mathrm{b}, \mathrm{i}, \mathrm{j}, \mathrm{k}}$
}

\begin{abstract}
Background: Cancer is a public health problem, especially in developing countries. In order to establish effective measures for the cancer control, there is a need for quality information, thus enabling a better understanding of the disease and its determinants, formulation of causal hypotheses, evaluation of the technological advances applied to prevention and treatment as well as the effectiveness of health care. The objective of the study was to investigate the prevalence of solid neoplasms diagnosed between the years 2011 to 2016 and treated at the Oncology Department of the University Hospital of Santa Maria and the existing oncological context.
\end{abstract}

Methods: This is an observational cross-sectional study. The target population was comprised of adult patients (18 years of age or older) and elderly people (60 years of age or older) diagnosed with solid cancer by anatomico-pathological examination between 2011 and 2016, who started oncological treatment, according to high complex-

Manuscript submitted January 30, 2019, accepted February 22, 2019

aDepartment of Oncology, University Hospital of Santa Maria, Federal University of Santa Maria (UFSM), Santa Maria, Rio Grande do Sul, Brazil

bPost-Graduate Program of Health Science, Federal University of Santa Maria (UFSM), Santa Maria, Rio Grande do Sul, Brazil

${ }^{\mathrm{c}}$ Department of Surgery, Medicine School of Federal University of Santa Maria (UFSM), Santa Maria, Rio Grande do Sul, Brazil

dinstitute of Exact Sciences and Geosciences, University of Passo Fundo (UPF), Passo Fundo, Brazil

ePost-Graduate Program in Teaching Science and Mathematics (ppgECM), University of Passo Fundo (UPF), Passo Fundo, Brazil

fDepartment of Mathematics, Franciscan University (UFN), Santa Maria, Brazil

gPot-Graduate Program in Mathematics and Science Teaching, Franciscan University (UFN), Santa Maria, Brazil

hPost-Graduate Program of Health and Life Sciences, Franciscan University (UFN), Santa Maria, Brazil

${ }^{i}$ Department of Surgery in Orthopaedic, Medicine School of Federal University of Santa Maria (UFSM), Santa Maria, Rio Grande do Sul, Brazil

jDepartment of Orthopaedic, University Hospital of Santa Maria (SOTHUSM), Federal University of Santa Maria (UFSM), Santa Maria, Rio Grande do Sul, Brazil

${ }^{k}$ Corresponding Author: Tiango Aguiar Ribeiro, 1000 Roraima Avenue, Federal University of Santa Maria (UFSM), Santa Maria, Rio Grande do Sul State, Brazil. Email: tiangoribeiro@hotmail.com

doi: https://doi.org/10.14740/jocmr3769 ity procedure authorization (APAC)/Oncology.

Results: A total of 2,757 patients were selected, of which 1,493 patients were female $(54.2 \%)$ and 1,264 male $(45.8 \%)$. The mean age at the time of initiation of treatment was 59.94 years for both sexes, with the $95 \%$ confidence interval $(59.44-60.44)$. The majority of patients were aged 61 - 70 years, totaling 747 patients, followed by 718 patients between 51 - 60 years. In all 31 primary sites identified the most prevalent one of neoplasms are breast, prostate, colorectal and lung; and most cases were stage IV (1,039 cases). A percentage of the number of cases of breast and esophageal cancer was higher than expected, and in contrast to a low percentage of hepatocarcinoma, kidney cancer and central nervous system tumors. The patients came from the entire area of the fourth Health Coordinating Area, where $100 \%$ of the municipalities referred to the institution, as well as other nine locations belonging to other coordinators.

Conclusion: Most of the data obtained are consistent with the Brazilian reality, not identifying any peculiar characteristic of this region of the study worthy of note, except for the difference in the prevalence of some types of cancer, a fact that deserves further studies. There were also no discrepancies in a regional analysis. Along with this work, it was possible to demonstrate the cancer situation and the profile of oncology patients attended at a reference center for 41 municipalities, mainly in the central region of Rio Grande do Sul state, which may be useful in the elaboration of public policies to modify the profile identified, and serve as the basis for further studies in this region.

Keywords: Prevalence; Cancer; Oncological context; Attention to health; APAC

\section{Introduction}

The appearance of a malignant tumor (cancer or malignant neoplasm) is influenced not only by biological and behavioral characteristics but also by social, political, environmental and economic conditions [1]. We observe that the Brazilian population, since the middle of the 20th century has undergone intense modifications. Improvements in basic sanitation and combating communicable diseases are a fact that leads to a change in the health profile of a population [2,3]. Thus, chronic diseases and their complications, with malignant neoplasms being one of 


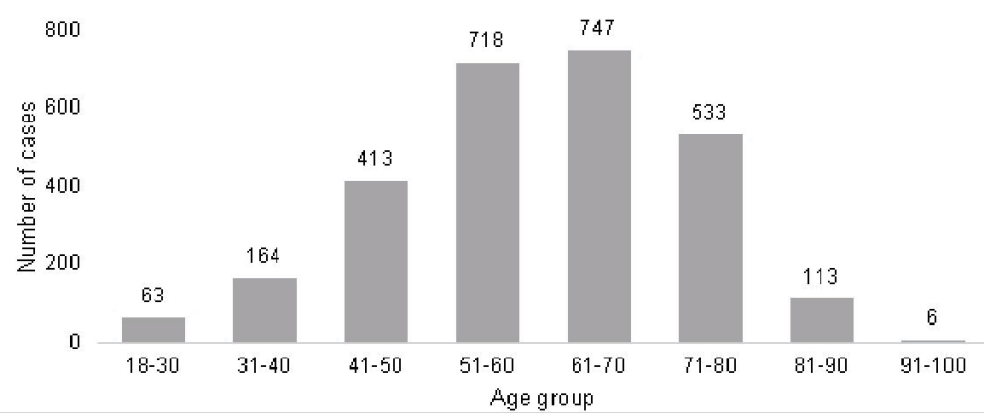

Figure 1. Number of patients per age group that started treatments in the service of Oncology at the University Hospital of Santa Maria from 2011 to 2016.

them, are more important in the health scenario of a nation [2].

In developing countries, it is estimated that in the coming decades the impact of cancer will reach $80 \%$ of tumors [4]. For this year (2019), the World Health Organisation (WHO) estimates that Brazil will have approximately 560 thousand new cases of cancer [5]. A marked heterogeneity of cancer morbidity and mortality among the different geographic regions of Brazil is observed [6]. In order to establish effective measures not only for the control of cancer but also for a more targeted diagnosis of the most common types present in a given region as well as for its prevention, it is necessary to know the quality information about the distribution of the incidence of this pathology [7]. The effective clinical management and an assessment of the needs and demands of the society require the use of health information at the local level, allowing health planners and managers to make decisions about the functioning of both services and the health system as a whole [8].

Thus, health information and knowledge should be used as strategic inputs, taking into account the resolubility of health actions [9]. To do so, we performed a cross-sectional observational study to determine the prevalence of solid neoplasms diagnosed and treated in a tertiary level and public hospital in southern Brazil.

\section{Materials and Methods}

A cross-sectional observational study was carried out after approval by the Research Ethics Committee (CAAE, number $2,211,192$ ) at the University Hospital of Santa Maria (HUSM), a tertiary level and hospital located in the south of Brazil. The study was carried out at the Oncology Department of this hospital, and respected the ethical precepts of the Declaration of Helsinki of 1975 . The study was carried out based on data collection in the Authorization of Procedures of High Complexity in Oncology (APAC/Oncology), document of the Ministry of Health for the release of cancer treatment (chemotherapy). The APACs for patients treated from June 2011 to May 2016 were analyzed. As an inclusion criterion for this study, the APAC patient should have the diagnosis of solid cancer made by anatomo-pathological examination and have performed the chemotherapy treatment in our hospital. As exclusion criterion patients with hematologic neoplasia (not solid tumors) and adolescent patients and children (below 18 years of age) were excluded.
Data regarding gender, date of birth, primary tumor site, treatment start date, tumor stage and histopathological type were collected in the APACs. For tumor staging, the classification of malignant tumors (TNM) [10] was used.

\section{Statistical analysis}

The processing and analysis of the collected data were carried out with the program SPSS 20.0 (Statistical Package for the social Sciences). The quantitative variables were described as normal through their mean and standard deviation, and when not normal through their median and interquartile. Qualitative variables were described by their absolute and relative frequency. An ANOVA test was used to observe the age difference between the sexes. To vary the homogenicity of groups a Levene test was used. Significant statistical differences were considered when the value of $\mathrm{P}$ was $<0.05$.

\section{Results}

A total of 3,475 patients were initially selected, of which 2,757 patients were analyzed and were part of the study. Seven hundred eighteen (718) patients were excluded from the study, according to the previously mentioned exclusion criteria, 98 due to age below 18 years and 620 patients due to hematological (non-solid) neoplasia. About the studied population, $1,493(54.2 \%)$ patients were female and 1,264 (45.8\%) were male. The mean age of the studied population at the time of the initiation of the treatment was $59.94 \pm 13.28$ years (mean \pm standard deviation), with the $95 \%$ confidence interval (59.44 60.44). The minimum age was 19 years, and the maximum age was 98 . In the female sex, we observed a mean age of 57.37 \pm 13.24 years, with a minimum age of 20 and a maximum of 98 years. In male patients, mean age observed was $62.97 \pm$ 12.66 years, with a minimum age of 19 and a maximum of 91 years old. A statistically significant difference of age between the sexes was observed $(\mathrm{P}<0.001)$, perhaps explained why the sex group is not homogeneous $(\mathrm{P}=0.004)$.

Most of the cases of solid cancer $(1,465 ; 53.13 \%)$ were observed between 51 and 70 years of age; with 747 patients (27.09\%) from 61 to 70 years old, and 718 patients (26.04\%) between 51 and 60 years old. Figure 1 shows more information 
about the age distribution and the number of treated patients for solid cancer.

A total of 31 primary sites were identified, with 823 $(29.85 \%)$ of the breast cancer cases being the most prevalent neoplasms, followed by prostate cancer in 385 cases $(38.9 \%)$, colorectal cancer in $352(12.78 \%)$ and $270(9.79 \%)$ cases of lung cancer. Out of the total of 2,757 cases, $25(0.91 \%)$ cases were classified as of unknown site or without location specification. More information on the primary sites of solid cancers and the number of cases in absolute and relative frequency is observed in Table 1.

Classified according to the gender, except for obvious anatomical reasons such as uterine cervix, uterus/endometrium, ovary, placenta, vagina and vulva in women and penis, testis and prostate in men, among the most prevalent breast cancer cases, we had $816(99.15 \%)$ cases in the female sex and seven $(0.85 \%)$ in the male, in cases of the total of 823 . Of the 352 colorectal cancer cases, $203(57.67 \%)$ were males and $149(42.33 \%)$ were females. In the 270 lung cancer cases, 104 $(38.52 \%)$ were females and $166(61.48 \%)$ were males. Some types were identified in only one sex; such as heart/mediastinum/pleura type in three $(0.11 \%)$ cases, thyroid gland in one $(0.04 \%)$ case and spinal cord in one $(0.04 \%)$ case were observed only in males. On the other hand, bone sarcoma and thymus cancer were identified in one $(0.04 \%)$ female patients. Figure 2 shows the sex-dependent distribution of some types of primary tumor site.

Based on the distribution of prevalence according to the time frame, there was a progressive increase in the number of cases that started treatment according to the APAC, from 425 patients in the first year of the study to 605 patients in the third year, with a subsequent plateau and a slight decrease until the fifth year, as shown in Figure 3.

According to the tumor stages, through the TNM classification [10], the majority of cases $(1,039 ; 37.69 \%)$ were classified as stage IV. A total of $52(1.89 \%)$ did not present the information in the APAC and four $(0.15 \%)$ cases did not apply the classification (Table 2 and Fig. 4).

Among the cases of mamma, the majority were initial stages (I/II), with $536(65.13 \%)$ of the 823 cases. Meanwhile, stage IV (advanced/metastatic) was more prevalent among prostate cancer $(161(41.82 \%)$ of the 385 cases), colorectal cancer (136 (38.64\%) of 352 cases) and among those of lung (187 (69.26\%) of the 270 cases), as shown in Figure 5.

Among the four most prevalent primary sites, the main histopathological diagnoses were as following, for breast cancer, $714(86.76 \%)$ cases of invasive ductal carcinoma, followed by invasive lobular carcinoma with 51 (6.20\%) cases, $47(5.71 \%)$ cases of other types of invasive carcinoma, and one $(0.12 \%)$ case of adenocarcinoma. Among the in situ, there were nine (1.09\%) ductal cases and one $(0.12 \%)$ lobular case. Among the cases of prostate cancer, there were $384(99.74 \%)$ cases of adenocarcinoma and one $(0.26 \%)$ case of neuroendocrine carcinoma. In cases of colorectal cancer, 350 of them $(99.43 \%)$ were adenocarcinomas and two $(0.57 \%)$ cases of gastrointestinal stromal tumor. Finally, among the cases of lung cancer, the most prevalent histopathological type was adenocarcinoma with 119 (44.07\%) of the 270 cases, followed by squamous cell carcinoma with 66 $(24.44 \%)$ cases, as demonstrated in Figure 6.
Table 1. Prevalence According to the Primary Site

\begin{tabular}{|c|c|c|}
\hline Primary site & Number & $\%$ \\
\hline Breast & 823 & $29.85 \%$ \\
\hline Prostate & 385 & $13.96 \%$ \\
\hline Colorectal & 352 & $12.77 \%$ \\
\hline Lung & 270 & $9.79 \%$ \\
\hline Head/neck & 155 & $5.62 \%$ \\
\hline Esophagus & 137 & $4.97 \%$ \\
\hline Stomach & 106 & $3.84 \%$ \\
\hline Uterine cervix & 104 & $3.77 \%$ \\
\hline Pancreas & 71 & $2.58 \%$ \\
\hline Bladder & 70 & $2.54 \%$ \\
\hline Ovary & 49 & $1.78 \%$ \\
\hline Skin & 49 & $1.78 \%$ \\
\hline Body uterus/endometrium & 33 & $1.20 \%$ \\
\hline Testicles & 31 & $1.12 \%$ \\
\hline Unknown/without specific location & 25 & $0.91 \%$ \\
\hline Sarcoma soft tissues & 20 & $0.73 \%$ \\
\hline Bile duct & 18 & $0.65 \%$ \\
\hline Anus/anal canal & 10 & $0.36 \%$ \\
\hline Liver & 8 & $0.29 \%$ \\
\hline Kidney & 7 & $0.25 \%$ \\
\hline Brain & 6 & $0.22 \%$ \\
\hline Small intestine & 6 & $0.22 \%$ \\
\hline Vulva & 6 & $0.22 \%$ \\
\hline Placenta & 5 & $0.18 \%$ \\
\hline Heart/mediastinum/pleura & 3 & $0.11 \%$ \\
\hline Penis & 3 & $0.11 \%$ \\
\hline Thyroid gland & 1 & $0.04 \%$ \\
\hline Spinal cord & 1 & $0.04 \%$ \\
\hline Bone & 1 & $0.04 \%$ \\
\hline Vagina & 1 & $0.04 \%$ \\
\hline Thymus & 1 & $0.04 \%$ \\
\hline Total & 2,757 & $100.00 \%$ \\
\hline
\end{tabular}

Regarding the municipalities that refer their patients to "Hospital Universitario de Santa Maria", a total of 41 municipalities performed referral between the study periods. They were: Agudo, Alegrete, Cacequi, Capao do Cipo, Dilermando de Aguiar, Dona Francisca, Faxinal do Soturno, Formigueiro, Itaara, Itacurubi, Itaqui, Ivora, Jaguari, Jari, Julio de Castilhos, Macambara, Manoel Viana, Mata, Nova Esperanca do Sul, Nova Palma, Paraiso do Sul, Pinhal Grande, Quevedos, Restinga Seca, Rosario do Sul, Santa Margarida do Sul, Santa Maria, Santana do Livramento, Santiago, Sao Francisco de Assis, Sao Gabriel, Sao Joao do Polesine, Sao Martinho da Serra, Sao Pedro do Sul, Sao Sepe, Sao Vicente do Sul, Silveira Martins, Toropi, Unistalda, Uruguaiana and Vila Nova do Sul. The 


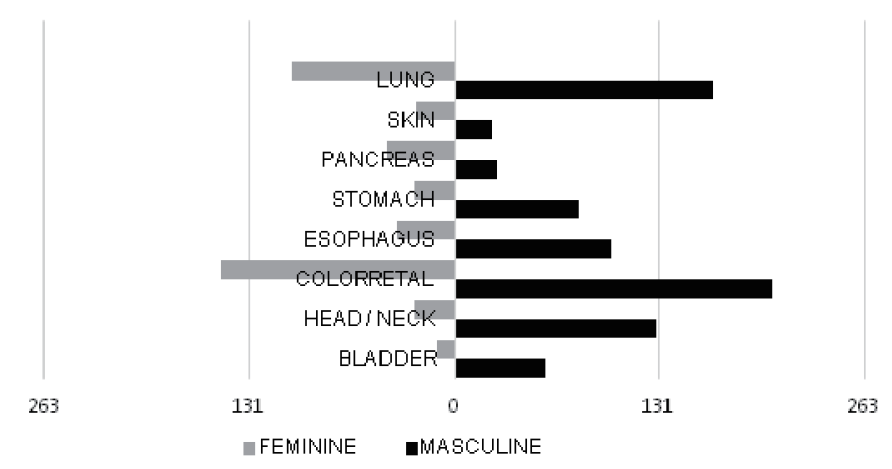

Figure 2. Comparison between tumor location and prevalence by sex.

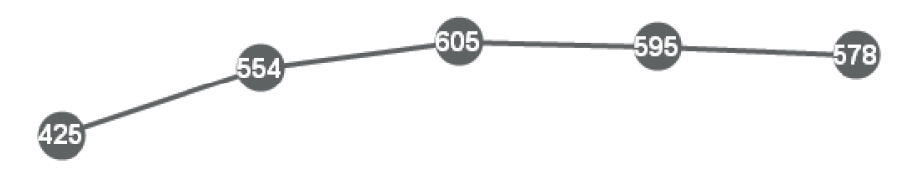

$\begin{array}{ccccc}01 / 06 / 2011- & 01 / 06 / 2012- & 01 / 06 / 2013- & 01 / 06 / 2014- & 01 / 06 / 2015- \\ 31 / 05 / 2012 & 31 / 05 / 2013 & 31 / 05 / 2014 & 31 / 05 / 2015 & 31 / 05 / 2016\end{array}$

Figure 3. Comparison between the number of patients who began treatment at the Oncology service by time frame.

municipalities that had the largest number of patients starting treatment at the institution according to APAC were: Santa Maria with 1,304 cases (47.3\%), followed by Santiago with 176 (6.4\%), Sao Sepe 141 (5.1\%), Sao Francisco de Assis 97 cases (3.5\%), Sao Gabriel 92 cases (3.3\%), Julio de Castilhos 87 (3.2\%), Sao Pedro do Sul 80 cases (2.9\%), Agudo with 78 (2.8\%), Restinga Seca 68 (2.5\%) and Jaguari 65 cases $(2.4 \%)$, according to Figure 7.

\section{Discussion}

In the population and in the period studied, with the knowledge

Table 2. Distribution of Cases According to Tumor Stage in Absolute Number and Percentage

\begin{tabular}{lll}
\hline Tumor stage & Number & \% \\
\hline I & 305 & $11.06 \%$ \\
II & 689 & $24.99 \%$ \\
III & 668 & $24.23 \%$ \\
IV & 1,039 & $37.69 \%$ \\
NA & 4 & $0.15 \%$ \\
NS & 52 & $1.89 \%$ \\
Total & 2.757 & $100.00 \%$ \\
\hline
\end{tabular}

NA: not applicable; NS: not stated. that the hospital analyzed is of tertiary level and reference for a population that can reach 541,247 people (according to the 2010 census) in the region of its health coordination, the female stood out in the prevalence of cases, with 1,493 (54.2\%) of the total of 2,757 patients. In the same way breast cancer was the most diagnosed tumor, representing 823 (29.85\%) of all cases; and stage IV was the most present stage independent of the diagnosed tumor type.

Consistent with Brazilian data and that from our state (Rio Grande do Sul) [11], female supremacy was observed in our study. However, these findings are contrary to those reported worldwide, where as a whole, males are the most affected by neoplasms [5].

Mean age at the time of initiation of treatment was higher in males, with 63 years as opposed to 57 years in females. This fact may explain why the gender group is not homogeneous; that is, there are differences in the participants of the groups. The minimum age was similar between the sexes and the maximum was higher in females $(98 \times 91$ years $)$. The majority of the patients were in the age group between 51 - 70 years, corresponding to 1,465 patients (53.72\% of the total). The data are consistent with the analysis of Rodrigues et al [12], although in our study we made use of a different age group, while Rodrigues et al [12] used age group between 45 - 64 years.

Among the primary sites diagnosed, a total of 31 were identified in APAC/Oncology, with the most prevalent neoplasms being in descending order: breast, prostate, colorectal and lung. The data are obtained from a document authorizing 


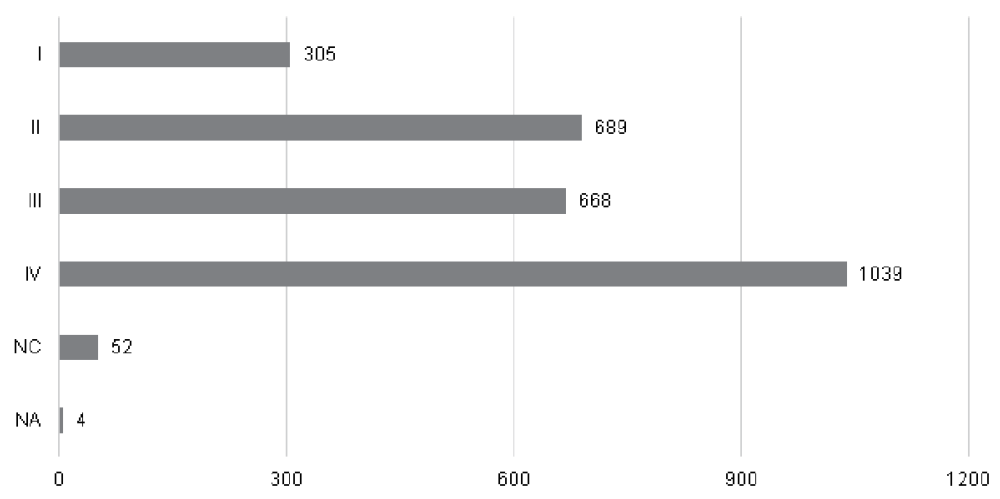

Figure 4. Distribution of cases according to tumor stage TNM classification [10].

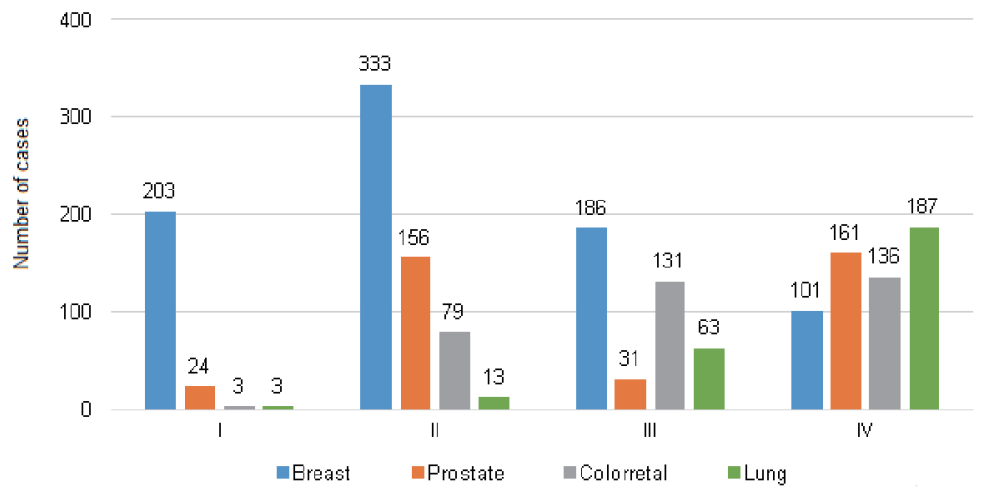

Figure 5. Distribution of the main primary sites according to the tumor stage.

treatment in the area of oncology in our country, so non-melanoma skin cancer which does not require treatment beyond surgical resection because of the characteristic of the neoplasia itself, is not related among the 31 sites reported in our study. Such order of prevalence of the major tumor sites was very similar to that found in the literature of the rest of the country [11]. This fact allows us to affirm that among the most prevalent sites found in our study there is no great difference with what is observed in the rest of the country. However, the percentage of cases observed in our study diverges further in cases of breast cancer $(29.85 \%)$ with the data from Kaercher et al [13] 2014

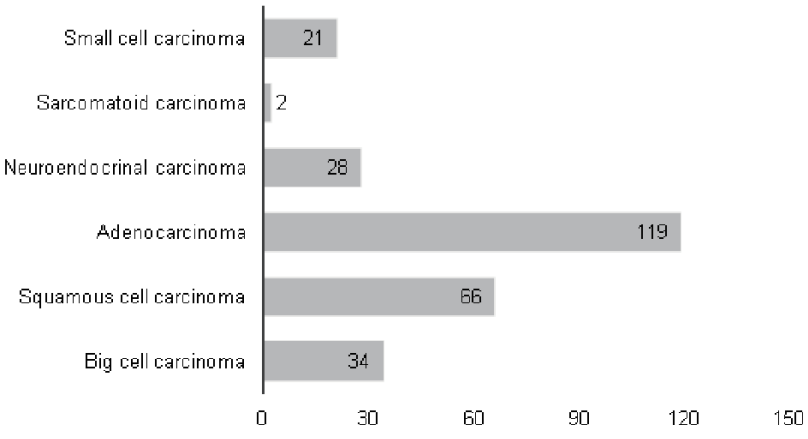

Figure 6. Histopathological types among cases of lung cancer.
(13\%), and the estimate of INCA [11] (approximately 14.3\% in Brazil and $12.6 \%$ in the South region, not counting non-melanoma skin cancer). This difference is also observed in cases of esophageal cancer, as $4.97 \%$ in our study compared to $2.6 \%$ in the study of Kaercher et al [13] 2014, and the estimate described in INCA [11] (approximately $2.59 \%$ in Brazil and 3\% , $7 \%$ in the South region). In esophageal tumors, an improved evaluation is required by subsequent studies to verify if the percentage found will be obtained in a global analysis of the cases, where patients who did not generate APAC in their treatment will be included (they did not require chemotherapeutic treatment ), being basically cases treated surgically. Already in cases of breast cancer, there is the bias of tumors that even in the initial stages needed oncological treatment that manages APAC, in this case the hormone therapy, which would justify this percentage higher than expected.

On the other hand, we observed a low percentage of central nervous system tumors $(0.22 \%)$, compared to INCA [11] (approximately $2.7 \%$ in Brazil and $3.2 \%$ in the south). Also the same trend was seen in kidney cancer $(0.25 \%)$ and in hepatocarcinoma $(0.29 \%)$, which is less than what the WHO estimated at $2 \%$ for both in 2018 . Better analysis in a later study is needed; but it may be justified in cases that are basically surgical or that require other treatments other than chemotherapy, hormone therapy or immunotherapy, not generating APAC and 


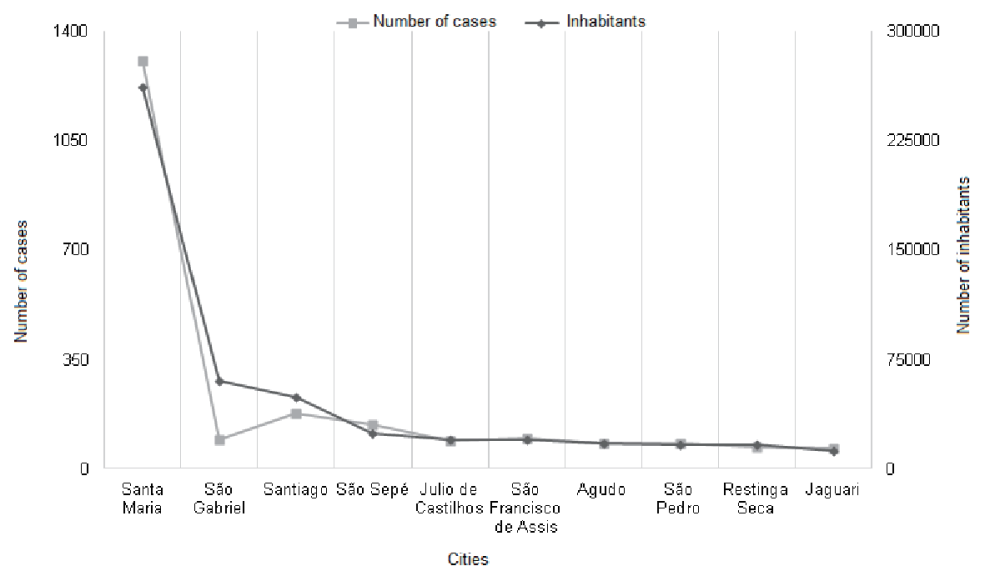

Figure 7. Relation between the number of inhabitants of the main cities that refer to the Oncology service of the Hospital Universitario de Santa Maria and the number of cases referenced between the years 2011 to 2016 .

consequently not being counted in this study.

Females had a higher prevalence of breast tumors, followed by colorectal tumors and lung tumors. This sequence is similar to that observed in Latin American and Caribbean countries, as well as in the world scenario as a whole $[4,5]$. However, this distribution differs in some points from the data observed for our country, where the first two placements (breast and colorectal) are similar; but the third most prevalent site in our country is thyroid compared to lung observed in our study, which is the fifth position in the national findings [11]. This difference can be explained due to the fact that in the great majority of cases, thyroid tumors do not require oncologic treatment, not generating APAC, which is a bias in our analysis, and may have generated this difference of tumor site positions.

Male patients had a higher prevalence of prostate tumors, followed by colorectal and lung tumors. These data corroborate with Brazilian statistics as shown by INCA [11] and WHO [5]. Also, in Latin American and Caribbean countries, the prostate is the most prevalent site in men [4]. We again observed the divergence with what was reported worldwide, where the most prevalent site for men is lung, followed by prostate and colorectal, such fact suggested by the anti-smoking measures in force in Brazil, according to WHO, 2018 [5].

Most of the patients who started treatment at the Oncology service of our hospital were diagnosed with advanced stage IV (according to the TNM), making a total of 1,039 (37.69\%) patients. This is considered an expected event, whereas the vast majority of tumors with early stages have their treatment almost exclusively surgical, with a less need for complementation through oncological drugs, which is the opposite of the more advanced stages. The data are divergent from that found in the study by Kaercher et al [13], in which the authors collected the data in medical records and not from APAC, with a higher prevalence of stage II. Then $52(1.89 \%)$ of cases did not have complete information in APAC, a fact generated by not correctly completing the document. But this does not affect the analysis of the tumor stage due to the large number of cases present in our study, and also by this absolute number of cases represents only $1.89 \%$ of the total cases, which would not sig- nificantly change the observed prevalence of stages.

Fragmenting the analysis by type of cancer, it is noticed that in the cases of mamma, the main stages found were initial II and I respectively, with fewer cases in more advanced stages, consistent with the data found in the study of Kaercher et al [13], 2014. For prostate, lung, and colorectal cases, most cases were stage IV at the beginning of treatment (with metastases already present). Comparing with the study by Kaercher et al [13], we observed a difference in prostate tumors in that the most prevalent stage in this study was II. In the other tumor types like lung and colorectal, the one observed by Kaercher et al [13] is similar to our findings.

On the other hand, the most important cases $(n=714)$ were ductal invasive carcinoma, followed by invasive lobular carcinoma, with 51 cases, in relation to the four main primary sites, in corroborating with the literature [4, 14]. Also seen in cases of prostate, almost all cases were adenocarcinoma with only one case of neuroendocrine carcinoma. Among the cases of colorectal cancer, the massive majority was of adenocarcinoma with 350 cases and only two of gastrointestinal stromal tumor, consistent with the literature [14]. In the cases of lung, the main histopathological diagnosis was adenocarcinoma (n $=119$ ), followed by squamous cell carcinoma/epidermoid with 66 cases. The profile found is consistent with what has been identified in recent years in developed countries, as well as in Brazil. Even though it is an underdeveloped country, due to the great efforts in anti-smoking actions, we have seen the altered epidemiology of lung cancer in recent years, with an increase in the incidence of adenocarcinoma and a decrease in squamous cell carcinoma according to Tsukazan et al [15].

Based on the distribution of prevalence according to the time frame, in the 5 years of study, there was a gradual increase in the number of patients who began treatment in the service in the first 3 years, between June 1, 2011 to May 31, 2014 which is in agreement with the world [5] and also with the Brazilian [7] statistics for the cancer. But this increase is followed by a subsequent stability and slight decrease in the number of cases in the subsequent 2 years. Unexpected fact due to the increasing number of new cases both in the world and in Brazil, but which can be justified by administrative, physical or personal struc- 
ture issues, which require future studies for better evaluation.

\section{Conclusions}

This research aimed to identify the prevalence of solid neoplasms diagnosed between 2011 and 2016 in an oncology service in the state of Rio Grande do Sul, with its oncological context. In our study, the female gender was the most prevalent one, in the same way that breast cancer was the most identified tumor in APACs (29.85\%), followed by prostate, colorectal and lung. In cases of lung, the main histopathological diagnosis was adenocarcinoma, followed by squamous cell carcinoma/epidermoid, consistent with what has been identified in recent years in developed countries, as well as in Brazil. In general, regardless of the type of tumor diagnosed, the majority of the patients who started treatment were in an advanced stage (stage IV).

The present study shows that in addition to breast cancer, esophageal cancer had a percentage higher than expected when compared to Brazilian statistics that did the analysis by other tools (without the use of APAC). There is a need for further studies to see if this index is maintained in an analysis encompassing cases that did not require treatments that generated APAC (basically surgical). On the other hand, a low percentage of tumors of the central nervous system, kidney cancer and hepatocarcinoma were obtained in the data of our study. Better analysis in a later study is needed.

Due to this work it was possible to demonstrate the cancer situation and the profile of oncology patients attended at a reference center for 41 municipalities, mainly in the central region of the state of Rio Grande do Sul, which may be useful in the elaboration of public policies to modify the profile identified, and serve as the basis for further studies in this region. The study also highlights the high incidence of cancer in the age group of 51 to 70 years $(53.72 \%)$ corresponding to a portion of the population still productive, since it identifies a longer life expectancy in the general population compared to previous decades. This fact may represent economic harm to society, as well as trigger family problems, where many of these patients are the providers of resources to their families, corroborating that neoplasias are currently considered a public health problem with important social repercussions.

\section{Acknowledgments}

None to declare.

\section{Financial Disclosure}

None to declare.

\section{Conflict of Interest}

The authors declare that they have no conflict of interest.

\section{Author Contributions}

Silva, FB: data collection. Silva, FB; Binato, M; Silva, JT; Marques, CT; and Ribeiro, TA: writing the paper, revising the paper and data analysis. All authors participated, reviewed and authorized the submission and the publication of the article.

\section{References}

1. Barreto ML, Carmo EH. Padroes de adoecimento e de morte da populacao brasileira: os renovados desafios para o Sistema Unico de Saude. Ciencia \& Saude Coletiva. 2007;12:1179-1790.

2. Carvalho JAMd, Rodriguez-Wong LL. A transicao da estrutura etaria da populacao brasileira na primeira metade do seculo XXI. Cadernos de Saude Publica. 2008;24:597605.

3. Casado L, Vianna LM, Thuler LCS. Fatores de risco para doencas cronicas nao transmissiveis no Brasil: uma revisao sistematica. Revista Brasileira de Cancerologia. 2009;55(4):379-388.

4. INCA I.N.d.C. Estimativa 2017: incidencia de cancer no Brasil 2015, Rio de Janeiro: Instituto Nacional de Cancer (INCA) Jose Alencar Gomes da Silva. Coordenacao de Prevencao e Vigilancia.

5. Internacional Agency for Research on Cancer: WHO, W.H.O. Globocan 2018. October 01, 2018; Available from: http://gco.iarc.fr.

6. Otero UB, et al. Aplicacao de uma metodologia de screening para avaliar a mortalidade por cancer em municipios selecionados do Estado de Minas Gerais, Brasil. Cadernos de Saude Publica. 2007;23:S537-S548.

7. INCA I.N.d.C. Estimativa 2010: incidencia de cancer no Brasil 2009, Rio de Janeiro: Instituto Nacional de Cancer (INCA) Jose Alencar Gomes da Silva. Coordenacao de Prevencao e Vigilancia.

8. AbouZahr C, Boerma T. Health information systems: the foundations of public health. Bull World Health Organ. 2005;83(8):578-583.

9. Cunha FJAP, Mendes VLPS. A politica nacional de informacao e informatica: uma base para a implantacao da gestao da informacao nos servicos de saude. 2005. September 25, 2016; Available from: http://www.cinform. ufba.br/v_anais/artigos/francisco.html.

10. Brierley JD, Gospodarowicz MK, Wittekind C. TNM Classification of Malignant Tumours. 8th Edition ed. 2017; Wiley-Blackwell. 272.

11. INCA I.N.d.C. Estimativa 2018: incidencia de cancer no Brasil 2017, Rio de Janeiro: Instituto Nacional de Cancer (INCA) Jose Alencar Gomes da Silva. Coordenacao de Prevencao e Vigilancia.

12. Rodrigues J, Ferreira N. Caracterizacao do perfil epidemiologico do cancer em uma cidade do interior paulista: conhecer para intervir. Revista Brasileira de Cancerologia. 2010;56(4):431-441.

13. Kaercher A, et al. The cancer hospital registry of a reference center in southern Brazil: analysis of the diagnoses 
over a 7-year period. Revista Brasileira de Oncologia Clinica. 2014;10(37):103-107.

14. Kumar V, Abbas A, Aster J. Robbins Basic Pathology. 9 ed. 2012.
15. Tsukazan MTR, Vigo A, Silva VDD, Barrios CH, Rios JO, Pinto JAF. Lung cancer: changes in histology, gender, and age over the last 30 years in Brazil. J Bras Pneumol. 2017;43(5):363-367. 